Technological Learning for Carbon Capture and Sequestration Technologies

Keywan Riahi, Edward S. Rubin, Margaret R. Taylor, Leo Schrattenholzer, and David Hounshell

RR-04-012

November 2004 



\title{
Technological Learning for Carbon Capture and Sequestration Technologies
}

\author{
Keywan Riahi ${ }^{a}$, Edward S. Rubin ${ }^{\mathrm{b}}$, Margaret R. Taylor ${ }^{\mathrm{b}, \mathrm{c}}$, \\ Leo Schrattenholzer ${ }^{\mathrm{a}}$, and David Hounshell ${ }^{\mathrm{b}}$ \\ a International Institute for Applied Systems Analysis, Laxenburg, Austria \\ ${ }^{b}$ Carnegie Mellon University, Pittsburgh, PA, USA \\ ${ }^{c}$ Berkeley, University of California, Berkeley, CA, USA
}

RR-04-012

November 2004

Reprinted from Energy Economics, 26(4):539-564 (2004).

International Institute for Applied Systems Analysis - Schlossplatz 1 - A-2361 Laxenburg - Austria Tel: (+43 2236) 807 • Fax: (+43 2236) 71313 •E-mail: publications@iiasa.ac.at•Web: www.iiasa.ac.at 
Research Reports, which record research conducted at IIASA, are independently reviewed before publication. Views or opinions expressed herein do not necessarily represent those of the Institute, its National Member Organizations, or other organizations supporting the work.

Reprinted from Energy Economics, 26(4), Keywan Riahi, Edward S. Rubin, Margaret R. Taylor, Leo Schrattenholzer, David Hounshell, Technological learning for carbon capture and sequestration technologies, pp. 539-564 (2004), with permission from Elsevier.

Copyright @ 2004 Elsevier B.V.

All rights reserved. No part of this publication may be reproduced or transmitted in any form or by any means, electronic or mechanical, including photocopy, recording, or any information storage or retrieval system, without permission in writing from the copyright holder. 


\title{
Technological learning for carbon capture and sequestration technologies
}

\author{
Keywan Riahi ${ }^{\mathrm{a}, *}$, Edward S. Rubin ${ }^{\mathrm{b}}$, Margaret R. Taylor ${ }^{\mathrm{b}, \mathrm{c}}$, \\ Leo Schrattenholzer ${ }^{\mathrm{a}}$, David Hounshell ${ }^{\mathrm{b}}$ \\ ${ }^{a}$ Environmentally Compatible Energy Strategies Project, \\ International Institute for Applied Systems Analysis (IIASA), Schlossplatz 1, 2361 Laxenburg, Austria \\ ${ }^{\mathrm{b}}$ Carnegie Mellon University, Baker Hall 128A, 5000 Forbes Avenue, Pittsburgh, PA 15213, USA \\ ${ }^{\mathrm{c}}$ Berkeley, University of California, Berkeley, CA 94720, USA
}

Available online 20 July 2004

\begin{abstract}
This paper analyzes potentials of carbon capture and sequestration technologies (CCT) in a set of long-term energy-economic-environmental scenarios based on alternative assumptions for technological progress of CCT. In order to get a reasonable guide to future technological progress in managing $\mathrm{CO}_{2}$ emissions, we review past experience in controlling sulfur dioxide $\left(\mathrm{SO}_{2}\right)$ emissions from power plants. By doing so, we quantify a "learning curve" for CCT, which describes the relationship between the improvement of costs due to accumulation of experience in CCT construction. We incorporate the learning curve into the energy-modeling framework MESSAGEMACRO and develop greenhouse gas emissions scenarios of economic, demographic, and energy demand development, where alternative policy cases lead to the stabilization of atmospheric $\mathrm{CO}_{2}$ concentrations at 550 parts per million by volume (ppmv) by the end of the 21 st century. We quantify three types of contributors to the carbon emissions mitigation: (1) demand reductions due to the increased price of energy, (2) fuel switching primarily away from coal, and (3) carbon capture and sequestration from fossil fuels. Due to the assumed technological learning, costs of the emissions reduction for CCT drop rapidly and in parallel with the massive introduction of CCT on the global scale. Compared to scenarios based on static cost assumptions for CCT, the contribution of carbon sequestration is about $50 \%$ higher in the case of learning, resulting in cumulative sequestration of $\mathrm{CO}_{2}$ ranging from 150 to 250 billion $\left(10^{9}\right)$ tons with carbon during the 21 st century. Also, carbon values (tax) across scenarios (to meet the $550 \mathrm{ppmv}$ carbon concentration constraint) are between $2 \%$ and $10 \%$ lower in the case of learning for CCT by 2100 . The results illustrate that assumptions on
\end{abstract}

* Corresponding author. Tel.: +43-2236-807-491; fax: +43-2236-807-488.

E-mail address: riahi@iiasa.ac.at (K. Riahi). 
technological change are a critical determinant of future characteristics of the energy system, indicating the importance of long-term technology policies in mitigation of adverse environmental impacts due to climate change.

(C) 2004 Elsevier B.V. All rights reserved.

Keywords: Carbon capture and sequestration; Technological learning; Climate change

\section{Introduction}

The mitigation of adverse environmental impacts due to climate change requires the reduction of carbon dioxide emissions from the energy sector, the dominant source of global greenhouse gas emissions. There are a variety of possibilities to reduce carbon emissions, ranging from the enhancement of energy efficiency to the replacement of fossilbased energy production by zero-carbon technologies. Most of the currently viable mitigation technologies, however, are more costly and inferior in some ways compared to the older and more "mature" fossil alternatives. Thus, there is an increasing interest among experts and policy makers in "add-on" environmental strategies to combine stateof-the-art fossil technologies with advanced technologies that capture carbon for subsequent sequestration. Such strategies, if successfully implemented, could enable the continuous use of fossil energy carriers at low (or almost zero) emissions.

Carbon capture and sequestration is not a completely new technology, e.g., the United States alone is sequestering about 8.5 million tons of carbon for enhanced oil recovery each year. Nevertheless, present costs for carbon capture technologies (CCT) to reduce emissions are between US\$35/t C and US\$264/t C (DOE, 1999), corresponding to a prohibitive cost increase for electricity of at least US\$25/MW h. Given the current costs, it is unlikely that CCT can successfully enter the energy market, even if international agreements and efficient institutions for $\mathrm{CO}_{2}$ abatement would exist. Their pervasive diffusion will require substantial efforts to induce "technological learning", which could accomplish considerable cost reductions in the long run.

With this perspective, this paper examines future market perspectives of carbon capture and sequestration by analyzing the dynamics, pace, and future potential for technological learning of CCT. Generally, costs - and other indicators of technology performanceimprove as experience is gained by producers (learning-by-doing) and consumers (learning-by-using). In order to get a reasonable guide to future technological progress of carbon capture technologies, we review past experience in controlling sulfur dioxide $\left(\mathrm{SO}_{2}\right)$ emissions from power plants. By doing so, we quantify a "learning curve" that we apply to CCT to describe the relationship between the improvement of costs due to accumulation of experience in CCT construction.

The long-term nature of climate change and its inherent uncertainties call for robust strategies taking into account a number of possible alternative futures. Hence, we incorporate the learning curve into the energy modeling framework MESSAGE-MACRO and develop a set of global greenhouse gas emissions scenarios of economic, demographic, and energy demand development, where alternative policy cases lead to the stabilization of atmospheric $\mathrm{CO}_{2}$ concentrations at 550 parts per million by volume (ppmv). Within 
this frame, we analyze the potential of CCTs in the context of other main mitigation options, such as fuel switching and enhanced energy conservation. As we shall show in this paper, under the assumption that learning in the application of CCT technologies occurs at a pace that is similar to that experienced for $\mathrm{SO}_{2}$ abatement technologies in the past, the long-term reduction potential for CCT is vast. Even though their widespread deployment requires decades to come, at the end of the 21 st century, almost all fossil power plants in the scenarios are equipped with CCT.

This paper is structured as follows: Section 2 describes how the learning curve for carbon capture and sequestration technologies was developed. A brief introduction into how technological learning is implemented into the MESSAGE-MACRO is given in Section 3. Section 4 presents our scenario analysis, including estimates of future potentials of carbon capture technologies. Section 4.1 summarizes the main characteristics of the baseline and mitigation scenarios. The main mitigation measures to decarbonize the future energy system are analyzed in Section 4.2, with Section 4.3 focusing mainly on the role of carbon scrubbing and sequestration. Finally, Section 5 concludes.

\section{Estimation of learning curves for carbon capture and sequestration technologies}

In 1936, a seminal paper by Wright (1936) introduced a quantitative model of "learning by doing" to describe the time savings (and associated cost reductions) achieved in manufacturing aircraft. Wright found that the time required to assemble an aircraft decreased with increasing production levels. The relationship was well-predicted by an equation of the form

$$
y=a x^{-b}
$$

where $a$ equals the costs (hours) to manufacture the first unit, $x$ depicts the cumulative number of units produced, $y$ is the costs (hours) required to produce unit number $x$, and $-b$ gives the slope for the improvement in costs (hours) in producing the units.

On a $\log -\log$ scale, this equation plots as a straight line with slope $-b$. Wright coined the term "progress ratio" to describe the ratio of current cost to initial cost after a doubling of production. Thus, a progress ratio of 0.80 meant that costs decreased by $20 \%$ for each doubling of cumulative production. Some authors therefore prefer the term "learning rate" for the latter quantity.

Wright's "learning curve" equation was subsequently found to describe the decline in production costs for a wide range of manufacturing activities remarkably well (e.g., Dutton and Thomas, 1984). The concept of learning-by-doing was further extended to model the anticipated capital cost reductions in new generations of a technology, including a variety of advanced energy technologies (Nakicenovic et al., 1998; McDonald and Schrattenholzer, 2001). In this paper, we measure the overall rate of progress or learning from its two principal components: new and improved generations of the technology and learning how to operate existing equipment more efficiently. These two components contribute to what is often referred to as "experience curves" that represent the change in technology cost as a function of its cumulative installed capacity (IEA, 2000). 
We have estimated learning rates of capital and operating cost reduction for the most common flue gas desulfurization (FGD) technology used at coal-fired power plants for $\mathrm{SO}_{2}$ capture. This FGD system employs a slurry of lime or limestone as the chemical reagent to absorb $\mathrm{SO}_{2}$ from flue gases. Fig. 1 shows the historical growth in installed capacity of these systems since they were first introduced in Japan in the late 1960s. The largest market has been the United States, which adopted stringent standards for $\mathrm{SO}_{2}$ control under the Clean Air Act Amendments of 1970 and 1977. A decade later, Germany adopted FGD systems as part of its acid rain control strategy. Subsequently, the technology was deployed more widely in Europe and elsewhere.

Both the capital and operating costs of FGD systems depend on a large number of plant-specific design and operating factors such as plant size, plant utilization, coal properties, emission reduction requirements, and other parameters (Rubin, 1983). To obtain a systematic measure of FGD cost reductions attributable solely to technology innovation, we used a set of engineering-economic analyses of new FGD systems applied to a fixed US plant design. These studies were performed primarily by two major utilityindustry organizations (the Tennessee Valley Authority [TVA] and the Electric Power Research Institute [EPRI]) at different points in time, using consistent methodologies and assumptions (McGlamery et al., 1976, 1980; Keeth et al., 1986, 1990, 1991, 1995). Thus, differences in FGD cost over time (adjusted for inflation) reflected real improvements in the cost of FGD technology for the standard plant application (i.e., $90 \% \mathrm{SO}_{2}$ removal at a new 500-MW plant burning a bituminous coal with 3.5\% sulfur and a plant capacity factor of $65 \%$ ). In a few cases, a power plant cost model (Rubin et al., 1997) was used to adjust reported cost figures to a consistent design basis where power plant design premises differed slightly from earlier studies.

Fig. 2 shows the resulting decline in FGD capital cost as a function of total cumulative capacity installed in the US, Germany, and Japan over the past several

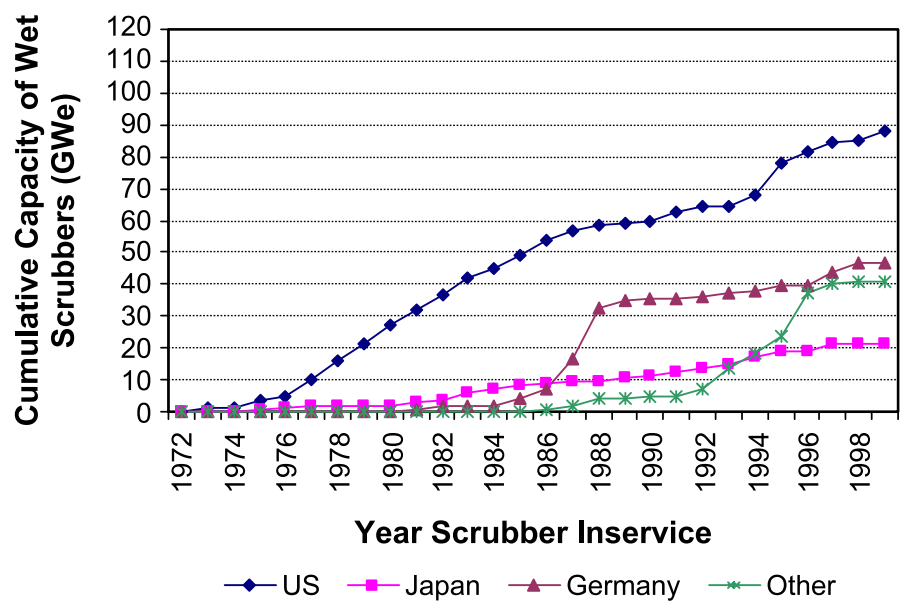

Fig. 1. Cumulative installed capacity of wet lime or limestone scrubbers in the US, Japan, Germany, and the rest of the world. Years after 1993 where under construction or firmly planned as of 1994 (source: Soud, 1994). 


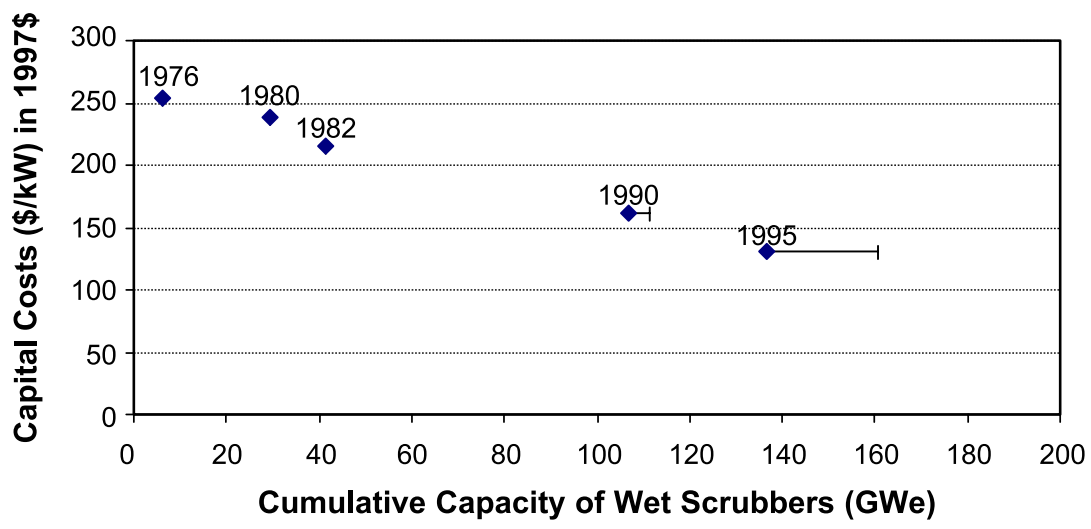

Fig. 2. Reductions in capital cost of a new wet limestone FGD system for a standardized coal-fired power plant (500 MWe, 3.5\% sulfur coal, $90 \% \mathrm{SO}_{2}$ removal). Cumulative GWe capacity based on wet lime/limestone scrubbers in the US, Germany, and Japan, with the error bars including the rest of the world.

decades. This measure of cumulative capacity was used as the basis for the estimation of an experience curve because other research showed that these three countries dominated (and shared) inventive activities and innovations in this technology (Taylor, 2001).

For the purposes of this study, the data in Fig. 2 was normalized and fitted with an equation of the form of Eq. (1) to obtain an experience curve showing the rate of cost decline with increasing capacity. This function shows that as cumulative worldwide scrubbed capacity doubled, capital cost declined to about $87 \%$ of its original value. This relationship (Fig. 3) is used in the MESSAGE-MACRO model to represent the expected cost decrease for $\mathrm{CO}_{2}$ capture systems in coal- and natural-gas-based power plants.

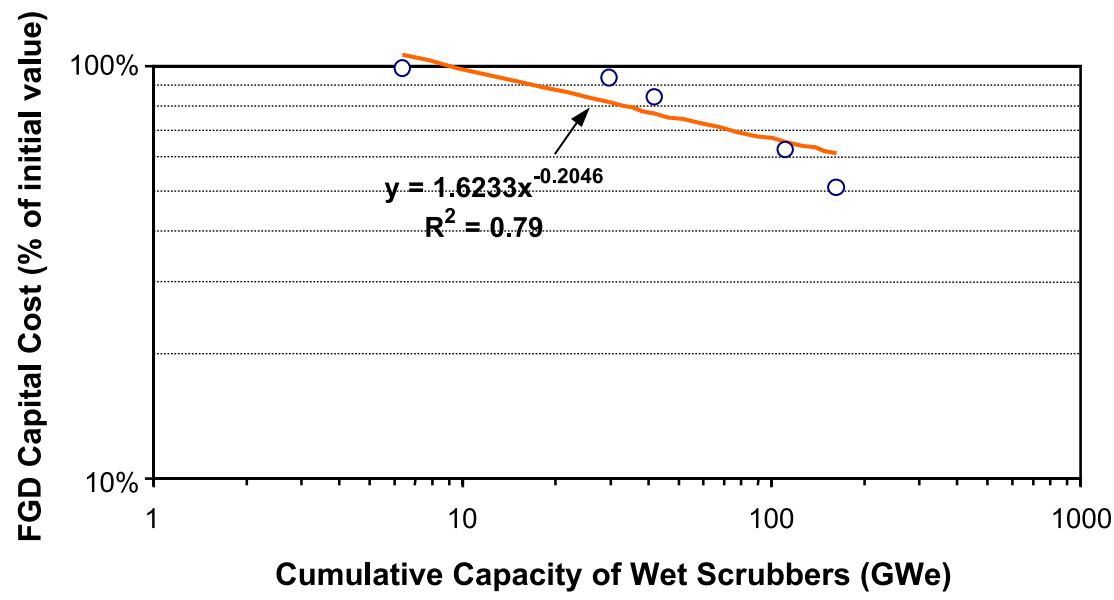

Fig. 3. Normalized experience curve for FGD capital cost. 


\section{Representation of technological change in MESSAGE-MACRO}

This section briefly summarizes the main features of the modeling framework MESSAGE-MACRO (Messner and Schrattenholzer, 2000), which was used for the development of the scenarios analyzed in this paper. In particular, we describe how the concept of technological learning is introduced into the models and give a brief description of the reference energy system with focus on the representation of carbon capture technologies.

The Systems Engineering Model MESSAGE (version IV) is a linear programming (LP) systems engineering optimization model, used for medium- to long-term energy system planning and policy analysis. The model minimizes total discounted energy system costs and provides information on the utilization of domestic resources, energy imports and exports and trade-related monetary flows, investment requirements, the types of production or conversion technologies selected (technology substitution), pollutant emissions, and interfuel substitution processes, as well as temporal trajectories for primary, secondary, final, and useful energy.

$M A C R O$ is a top-down macroeconomic model. In the form it is as it is used here, it has its roots in a long series of models by Manne et al. The latest model in this series is MERGE 4.5 (Manne and Richels, http://www.stanford.edu/group/MERGE/). Its objective function is the total discounted utility of a single representative producerconsumer. The maximization of this utility function determines a sequence of optimal savings, investment, and consumption decisions. In turn, savings and investment determine the capital stock. The capital stock, available labor, and energy inputs determine the total output of an economy according to a nested constant elasticity of substitution (CES) production function. Energy demand in two categories (electricity and nonelectric energy) is determined within the model, consistent with the development of energy prices and the energy intensity of GDP. When MACRO is linked to MESSAGE, internally consistent projections of realized GDP and energy demand are calculated in an iterative fashion that takes price-induced changes of demand and GDP into account.

A typical model application is constructed by specifying performance characteristics of a set of technologies and defining a reference energy system (RES) that includes all the possible energy chains that MESSAGE can make use of. In the course of a model run MESSAGE will then determine how much of the available technologies and resources are actually used to satisfy a particular end-use demand, subject to various constraints, while minimizing total discounted energy system costs. A simplified illustration of the MESSAGE reference energy system is shown in Fig. 4. The gray box (Fig. 4) shows where the carbon capture technologies (CCT) are linked into the reference energy system. In sum, MESSAGE distinguishes between three types of CCTs:

(1) carbon capture from conventional coal- and natural-gas-based power plants (flue gas decarbonization)

(2) carbon capture from coal-based integrated gasification combined cycles (IGCC)

(3) carbon capture during the production of synthetic gaseous and liquid fuels (predominantly hydrogen and methanol) 


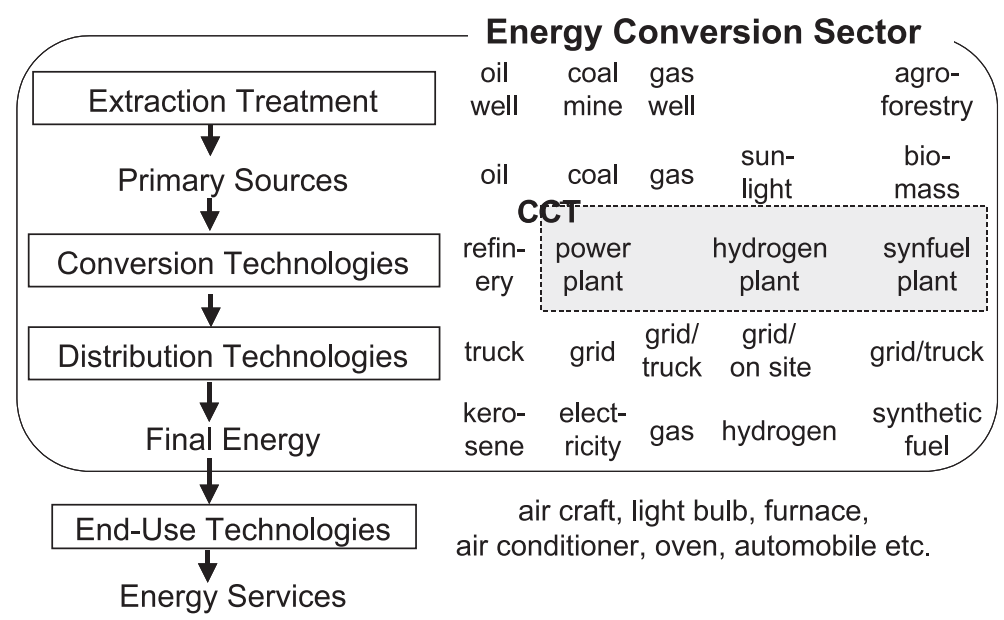

Fig. 4. Schematic illustration of the Reference Energy System (RES) in MESSAGE.

Important inputs for MESSAGE are technology costs and other technology parameters, which are taken from the energy technology database CO2DB ${ }^{1}$ (Strubegger et al., 1999). For the scenarios included in this paper, technical, economic, and environmental parameters for over 400 energy technologies are specified explicitly in the model. Costs of technologies are assumed to decrease over time as experience (measured as a function of cumulative output) is gained. ${ }^{2}$ As described earlier (Section 2), the relationship between costs and cumulative deployment of individual technologies is described by learning curves, characterized by a single learning rate and initial unit cost. However, assuming fixed learning rates ex ante is not possible within an LP formulation, because of the nonlinearity of the relationship and the resulting nonconvexity of the optimization problem, which would have to be tackled for example with Mixed Integer Programming (MIP). Illustrative MIP versions of MESSAGE to endogenize technological change through uncertain returns from learning have been developed (Messner, 1997) but are computationally infeasible for the detailed scenarios described in this study (which include over 400 energy technologies and operate on 11 world regions).

Thus, an iterative, "ex post" approach was used to obtain scenario results with the fullscale MESSAGE model, where technological improvements follow patterns consistent with those of learning curves. For this purpose, we assume that specific costs of technologies decrease at predefined rates over time. Such a time profile of costs will at first not necessarily mimic the behavior as postulated by learning curves. Hence, we increase the consistency of MESSAGE results with the learning-curve concept by

\footnotetext{
${ }^{1}$ CO2DB currently includes more than 1600 technologies and associated information on their recent, current, and projected costs, efficiencies, and environmental characteristics.

2 Note that cost improvements for specific technologies differ from scenario to scenario, representing alternative pathways for technological change consistent with the respective scenario storyline (narrative). Hence, we do not assume cost improvements for the whole set of 400 technologies in each scenario. In some cases, costs are assumed to stay constant, in particular for mature technologies, which are phased out early in time.
} 


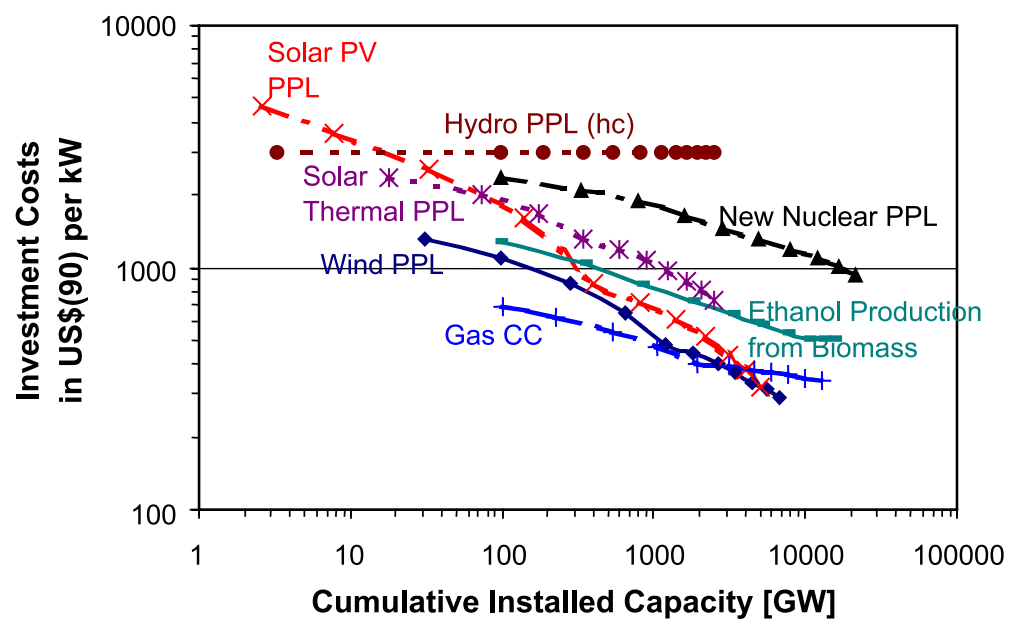

Fig. 5. Examples of investment cost (1990-2100) as implemented in MESSAGE. Literal learning curve would appear as straight lines on this double-log scale. Abbreviations: PV: photovoltaic, PPL: power plant, Gas CC: gas combined cycle power plant, New Nuclear PPL: future design of a new nuclear reactor.

iteratively adjusting technology costs and cumulative installed capacities. This approach is made possible with additional dynamic market penetration constraints in order to avoid "flip-flop" behavior for the most important technologies and to emulate the initial slow growth in niche markets of newly introduced technologies due to upfront investments. Fig. 5 shows examples of resulting cost decrease curves vs. cumulative installed capacities in a typical baseline scenario. Since investment costs are a power function of cumulative installed capacities, they appear as straight lines when plotted with double-logarithmic axis. All in all, the results in Fig. 5 show that the unit costs for the main technologies follow roughly a dynamics consistent with learning curves. ${ }^{3}$

\section{Long-term perspectives for carbon capture and sequestration technologies}

In order to estimate future potentials of CCT technologies, a set of global greenhouse gas emissions scenarios of economic, demographic, and energy demand development are analyzed. Frequently, scenario analyses are based on a static view of CCT technologies, where technology costs and performance are assumed to stay constant over time. Hence, important feedbacks on technology characteristics of, e.g., gaining experience in CCT construction and accumulated knowledge due to targeted R\&D efforts, are often not taken into account. We will analyze the future prospects of CCT technologies using a more dynamic representation of technology, where costs improve as a function of cumulative experience (i.e., CCT deployment).

\footnotetext{
${ }^{3}$ Although the applied methodology permits the emulation of the learning process, in some cases, the resulting learning curves deviate slightly from the classical straight line in a double-log scale (see, e.g., wind, nuclear, and solar PV in Fig. 5).
} 
Our assumptions on the learning potential for CCT are guided by the past experience of sulfur abatement technologies (see Section 2). In particular, we compare scenario results including learning for CCT technologies with scenarios based on static cost assumptions, and study the market potentials, costs, and impacts of CCT as a long-term carbon abatement technology.

For this purpose, we selected two baseline scenarios of the IPCC Special Report of Emissions Scenarios (IPCC, 2000) as our reference scenarios. For each, we develop two carbon mitigation scenarios (one with and one without CCT learning) aiming at the stabilization of atmospheric carbon concentrations at about 550 ppmv. The sequel of this section first presents the main characteristics of the respective baseline and carbon mitigation scenarios, proceeding later to the implications for CCT.

\subsection{Baseline reference scenarios}

Baseline assumptions of technological and socioeconomical development are paramount drivers of future GHG emissions, strongly influencing the choice of emissions mitigation strategies. As shown by the recent set of IPCC baseline scenarios (IPCC, 2000), the uncertainty associated with the drivers as well as the future GHG emissions is vast. In order to obtain a plausible range of estimates for the deployment of CCT, we analyze two alternative baseline scenarios, depicting future worlds of increasing carbon emissions with presumably high impacts due to climate change.

Both baseline scenarios are selected from the set of 40 IPCC-SRES reference scenarios. The B2-MESSAGE scenario (Riahi and Roehrl, 2000a) was selected because it is a kind of "middle-of-the-road" (dynamics-as-usual) scenario. In addition, we selected the A2MESSAGE scenario (Riahi and Roehrl, 2000b), since A2 portrays a fossil-intensive future characterized by heavy reliance on coal-based energy production. A2 and B2 are based on different assumptions of socioeconomic development, technological progress, and political change. They result in widely differing world energy systems, which are costoptimal strategies under the given assumptions, and lead to a wide range of emissions levels (Fig. 6). Assumptions for the main scenario drivers and results are presented in Table 1.

\subsubsection{The A2 baseline scenario (narrative)}

The A2 world represents a differentiated world, which "consolidates" into a series of economic regions. Economic growth is uneven across regions, and the income gap between poor and rich regions does not narrow as much as in the other SRES scenarios. Global average per capita income in A2 is low relative to B2, and global gross domestic product (GDP) reaches about US\$243 trillion. International disparities in productivity, and hence income per capita, are largely maintained or increased in absolute terms. ${ }^{4}$ Fertility rates decline relatively slowly, which leads to a steadily increasing world population reaching 15 billion by 2100 .

\footnotetext{
4 When not mentioned explicitly otherwise, gross world product (GWP), gross domestic product (GDP), and related parameters are reported at market exchange rates, in 1990 US\$.
} 


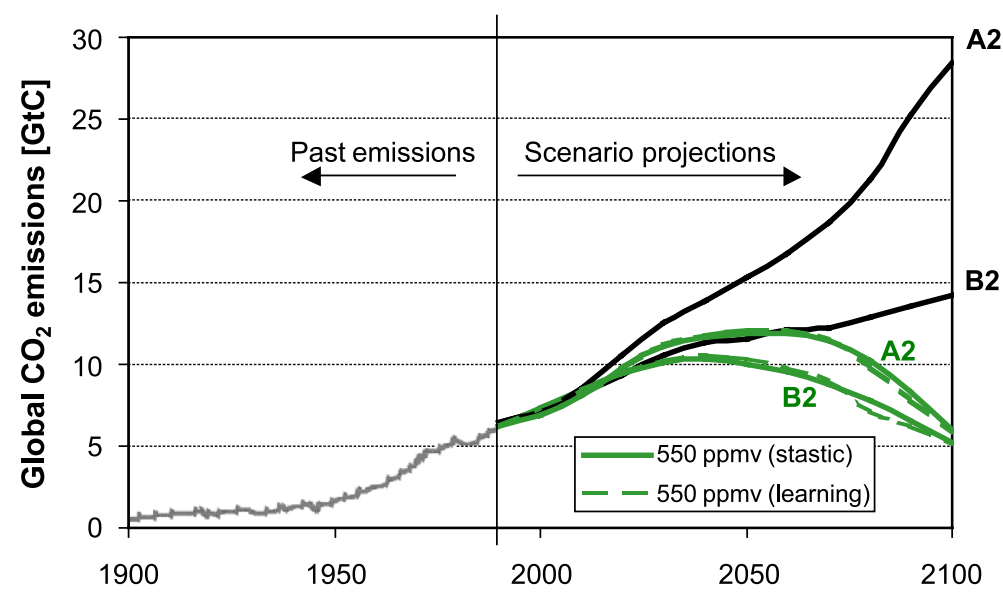

Fig. 6. Global carbon dioxide emissions in the A2 and B2 baseline scenarios and in the respective stabilization scenarios with and without learning for CCT.

A combination of slow technological progress, more limited environmental concerns, and low land availability because of high population growth means that the energy needs of the A2 world are satisfied primarily by fossil (mostly coal) and nuclear energy. However, in some cases, regional energy shortages force investments into renewable alternatives, such as solar and biomass. Regions with abundant energy and mineral resources evolve to more resource-intensive economies, while those poor in resources place a very high priority on minimizing import dependence through technological innovation to improve resource efficiency and make use of substitute inputs. The fuel mix in different regions is determined primarily by resource

Table 1

Overview of scenario drivers and results

\begin{tabular}{|c|c|c|c|c|c|c|c|}
\hline \multirow[b]{3}{*}{ Scenario } & \multirow[t]{3}{*}{ Year } & \multicolumn{2}{|c|}{ Baseline scenarios } & \multicolumn{4}{|c|}{ Stabilization scenarios } \\
\hline & & \multirow[b]{2}{*}{ A2 } & \multirow[b]{2}{*}{ B2 } & \multicolumn{2}{|c|}{ Static CCTs } & \multicolumn{2}{|c|}{ Learning CCTs } \\
\hline & & & & $\mathrm{A} 2-550 \mathrm{~s}$ & $\mathrm{~B} 2-550 \mathrm{~s}$ & A2-550t & $\bar{B} 2-550 \mathrm{t}$ \\
\hline \multirow[t]{2}{*}{ Population (billion) } & 2050 & 11.3 & 9.4 & 11.3 & 9.4 & 11.3 & 9.4 \\
\hline & 2100 & 15.1 & 10.4 & 15.1 & 10.4 & 15.1 & 10.4 \\
\hline \multirow{2}{*}{$\begin{array}{l}\text { Global gross domestic } \\
\text { product (trillion } 1990 \text { US\$) }\end{array}$} & 2050 & 82 & 110 & 81 & 109 & 81 & 109 \\
\hline & 2100 & 243 & 235 & 236 & 231 & 237 & 231 \\
\hline \multirow[t]{2}{*}{ Primary energy $(\mathrm{EJ})$} & 2050 & 1014 & 869 & 959 & 881 & 960 & 883 \\
\hline & 2100 & 1921 & 1357 & 1571 & 1227 & 1636 & 1257 \\
\hline $\begin{array}{l}\text { Cumulative carbon } \\
\text { emissions (Gt C) }\end{array}$ & $1990-2100$ & 1527 & 1212 & 992 & 948 & 990 & 950 \\
\hline $\begin{array}{l}\text { Cumulative carbon } \\
\text { sequestration (Gt C) }\end{array}$ & $1990-2100$ & - & - & 167 & 90 & 243 & 137 \\
\hline Carbon concentrations (ppmv) & 2100 & 783 & 603 & 550 & 550 & 550 & 550 \\
\hline
\end{tabular}

Compare with 1990 values for population (5.3 billion), GDP (US\$20.9 trillion [1990]), primary energy (352 EJ), total $\mathrm{CO}_{2}$ emissions $(6.2 \mathrm{Gt} \mathrm{C}), \mathrm{CO}_{2}$ concentration (354 ppmv). 
availability (limited to conventional reserves and resources). High-income but resource-poor regions shift toward advanced post-fossil technologies, while lowincome resource-rich regions generally rely on traditional fossil technologies. The A2 world is characterized by relatively slow end-use and supply-side energy efficiency improvements and slow convergence between regions. All this leads to steadily increasing levels of GHG emissions (Fig. 6), with $\mathrm{CO}_{2}$ emissions approaching $28 \mathrm{Gt} \mathrm{C}$ in 2100 .

\subsubsection{The B2 baseline scenario (narrative) ${ }^{5}$}

In the B2 world, GDP grows from US\$20 trillion in 1990 to US\$235 trillion in 2100 (Table 1). This corresponds to a long-term average growth rate of $2.2 \%$ from 1990 to 2100. Most of this growth takes place in today's developing countries, but over the long term, economic growth rates in these regions also decline as labor productivity levels approach those of the leading countries. The B2 scenario uses the UN median 1998 population projection (UN, 1998), which describes a continuation of historical trends, including recent faster-than-expected fertility declines, toward a completion of the demographic transition within the next century. Global population increases to 10.4 billion by $2100 .{ }^{6}$ Global primary-energy needs increase by almost a factor of 4 (in comparison to 1990) to $1360 \mathrm{EJ}$ in 2100. Most of this increase takes place in today's developing regions. The aggregate global rate at which final-energy intensity declines is about $1 \%$ per year through 2100. Cost improvement rates for most technologies are moderate; however, they are largest for non-sulfur-emitting technologies due to local and regional pollution control. These include, in particular, wind and solar photovoltaics, but also gas combined-cycle, integrated gasification combined cycle (IGCC), solar thermal power plants, and advanced nuclear power plants. ${ }^{7}$ Coal costs increase in regions with large shares of deep mined coal and high population densities, although coal costs are assumed to remain relatively low in regions with abundant surface coal reserves such as North America and Australia. Altogether, the B2 scenario exhibits linearly increasing global GHG emissions (Fig. 6), with $\mathrm{CO}_{2}$ emissions reaching $14 \mathrm{Gt}$ C by 2100 .

\subsection{Carbon mitigation scenarios}

In order to study future potentials for CCT technologies, we developed carbon mitigation scenarios aiming at the stabilization of atmospheric $\mathrm{CO}_{2}$ concentrations at about 550 ppmv. In sum, two stabilization scenarios for each baseline were developed-

\footnotetext{
5 See Riahi and Roehrl (2000a) for more details.

6 Although, in the long term, global fertility levels gradually approach replacement levels, the path and pace of fertility change vary greatly among the regions.

7 Advanced nuclear power plants are defined as technologies that produce energy with higher efficiency and increased safety compared to today's nuclear standards. Their technological design is not prespecified in the model. Advanced nuclear technologies should be interpreted as a technology cluster (consisting of various different designs) rather than a single individual technology. The cluster might include, e.g., efficient hightemperature reactors (that produce hydrogen), new fast breeder reactors with modified designs, but also other imaginable options for nuclear fission.
} 
one assuming constant costs for CCTs (A2-550s, B2-550s) and one including learning for CCTs (A2-550t, B2-550t).

All four stabilization scenarios are based on iterated runs of MESSAGE and MACRO. The macroeconomic model MACRO is important in this connection because the carbon constraint increases energy prices, which reduces energy demand and increases the demand for the other production factors (capital and labor), other things being equal. MACRO calculates this macroeconomic effect. Because both MESSAGE and MACRO are global optimization models, the model results are cost-optimal actions to meet the given carbon constraint. The results assume full spatial and temporal flexibility, including the free movement of investments. However, cost-optimal $\mathrm{CO}_{2}$ emissions reduction possibilities do not necessarily occur in regions that give high priority to such reductions and that have the money to pay for them. Indeed, currently, the cheapest $\mathrm{CO}_{2}$ reduction opportunities appear to be in developing countries, while it is the industrialized countries that currently appear most willing to pay for them. The stabilization scenarios can thus be seen as possible answers to the question: "Which are the best strategies to achieve stabilization if the world generally consistent with the (respective) baseline was able to successfully coordinate and cooperate on efforts to limit potential global warming?"

The resulting $\mathrm{CO}_{2}$ emissions trajectories of the mitigation scenarios are shown in Fig. 6. They are characterized by a peak of about 9-12 Gt C around the middle of the 21 st century. Subsequently, emissions decline to slightly less than the 1990 emissions level (6 Gt C) by 2100. These emissions profiles are similar to other emissions trajectories for 550 ppmv stabilization cases found in the literature (Wigley et al., 1996; Roehrl and Riahi, 2000). The similarity of the emissions pathways indicates limited flexibility of the timing and pace of emissions trajectories, to achieve $\mathrm{CO}_{2}$ concentration stabilization at $550 \mathrm{ppmv}$ with the least effort. Furthermore, the development of emissions is quite similar through 2020 in the stabilization runs and their baseline counterparts. Only after 2020 do emissions reductions become more pronounced. This is partly because power plants have lifetimes on the order of 30-40 years, which makes for slow turnover in the energy capital stock, and partly because of the temporal flexibility built into the concentration constraint. MESSAGE is free to choose when and where to reduce carbon emissions, and later reductions coinciding with turnover in capital plant are usually cheaper because of both technological progress and discounting. ${ }^{8}$

Although the resulting emissions trajectories of the four stabilization scenarios are similar, the contributions of individual mitigation measures to bring down emissions differ significantly. In particular, the choice of the mitigation strategy and the widespread deployment of specific mitigation options depend strongly on two factors:

(1) the socioeconomic and technological assumptions in the baseline scenarios and

(2) the assumptions with respect to technological learning for CCT technologies

We shall now discuss specific contributions of main mitigation options.

\footnotetext{
${ }^{8}$ For the scenarios presented in this paper, a discount rate of 5\% was applied.
} 


\subsection{Three kinds of mitigation measures}

In general, strategies to mitigate $\mathrm{CO}_{2}$ emissions may be based on technological change, economic incentives, and institutional frameworks. They range from using the carbon sequestering potential of afforestation to demand-side- or supply-side-oriented measures in the energy sector, and even so-called geo- and cosmo-engineering schemes (Nakicenovic et al., 1993). Here, we confine our discussion to $\mathrm{CO}_{2}$ abatement measures in the energy sector.

Applying the carbon concentration constraint to the baseline scenarios results in significant changes of energy demand and technology mix. Compared to the respective baseline scenarios, three principal contributors were identified by MESSAGE and MACRO as the most cost-effective route to meet the required stabilization target:

- fuel switching away from carbon-intensive fuels such as coal,

- scrubbing and removing $\mathrm{CO}_{2}$ in power plants and during the production of synthetic fuels, mainly methanol and hydrogen, and

- lower energy demand (enhanced energy conservation) of the stabilization case compared to the baseline counterpart, due to higher energy costs in the stabilization cases compared to their baseline scenario counterparts.

The carbon reductions of specific mitigation measures in the stabilization scenarios are summarized in Table 2. In all stabilization scenarios, the comparatively largest contribution comes from structural changes in the energy system. Principally, this is a shift away from coal, which has the highest $\mathrm{CO}_{2}$ emissions per unit of energy. To satisfy the carbon constraint, all mitigation scenarios make pronounced shifts to less carbon-intensive primary energy resources, and coal's share of primary energy decreases considerably.

The second most important contribution is due to carbon capture and sequestration, where the emission reductions are particularly high in the case of learning CCT technologies. Cost improvements in the case of technological learning for CCT result in additional markets for carbon capture and enable comparatively higher shares of fossil energy production, compared to the cases with static CCT costs. The contribution of main carbon capture technologies relative to other mitigation measures is shown in Fig. 7 for the A2-550t and in Fig. 8 for B2-550t, respectively.

Table 2

Emissions reductions (in Gt C) of the main mitigation measures in the stabilization scenarios for the years 2050 and 2100

\begin{tabular}{|c|c|c|c|c|c|c|c|c|}
\hline & \multicolumn{2}{|c|}{ Demand reduction } & \multicolumn{2}{|c|}{ Fuel switching } & \multicolumn{2}{|c|}{$\mathrm{CO}_{2}$ capture and sequestration } & \multicolumn{2}{|l|}{ Total } \\
\hline & 2050 & 2100 & 2050 & 2100 & 2050 & 2100 & 2050 & 2100 \\
\hline \multicolumn{9}{|c|}{ Static CCTs } \\
\hline A2-550s & 0.3 & 3.6 & 2.2 & 12.5 & 0.5 & 5.8 & 3.0 & 21.9 \\
\hline B2-550s & 0.3 & 1.3 & 1.4 & 3.9 & 0.3 & 3.0 & 2.0 & 8.2 \\
\hline \multicolumn{9}{|c|}{ Learning CCTs } \\
\hline A2-550t & 0.3 & 3.7 & 2.1 & 9.5 & 0.4 & 8.9 & 2.9 & 22.0 \\
\hline B2-550t & 0.3 & 1.5 & 1.1 & 4.0 & 0.3 & 4.0 & 1.7 & 9.5 \\
\hline
\end{tabular}




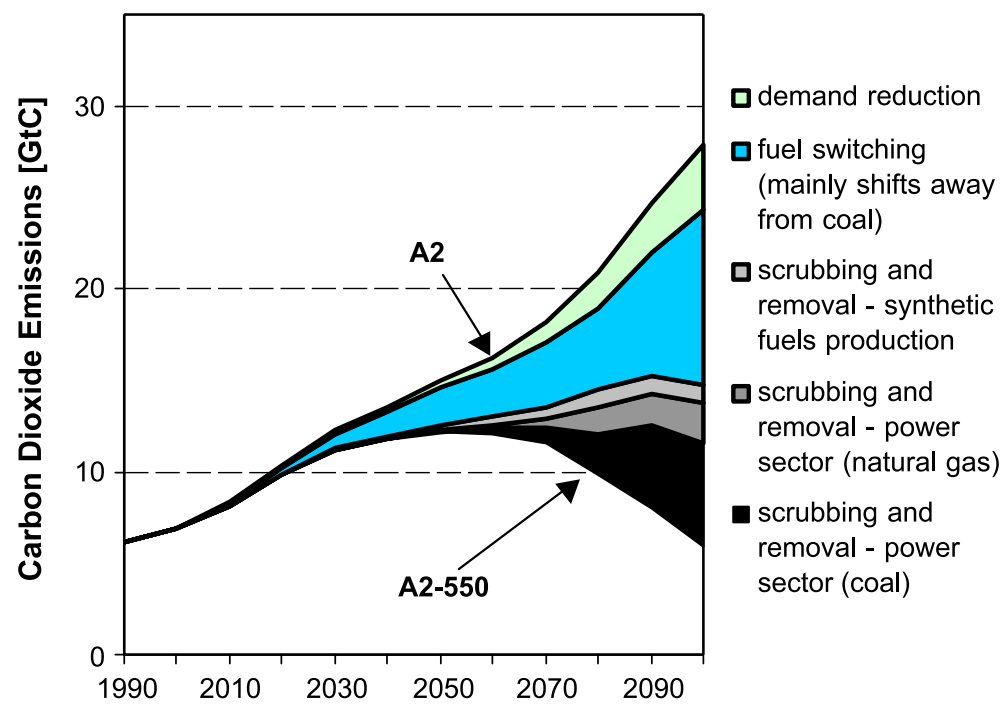

Fig. 7. $\mathrm{CO}_{2}$ emissions in the $\mathrm{A} 2$ baseline scenario and in the $\mathrm{CO}_{2}$ mitigation scenario in the case of learning CCTs (A2-550t). The shaded areas depict sources of $\mathrm{CO}_{2}$ reductions in the global energy system of the mitigation scenario, compared to the baseline scenario.

As regards the timing of the mitigation measures, the first half of the century is dominated by structural shifts in the energy system, which is mainly due to the widespread diffusion of gas-combined-cycle (GCC) power plants at the expense of

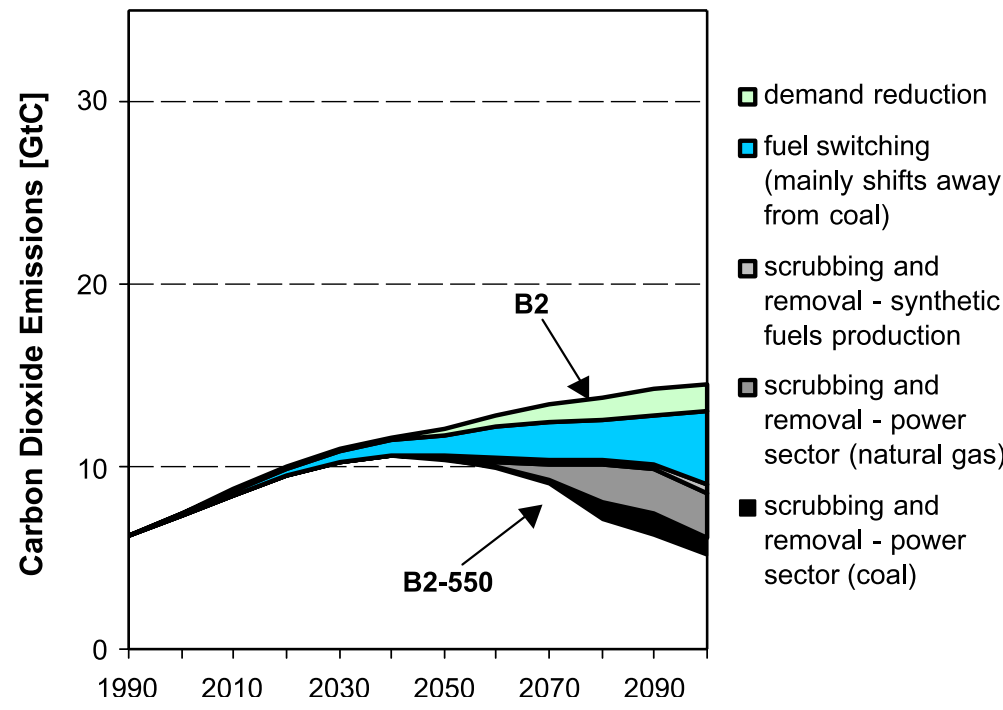

Fig. 8. $\mathrm{CO}_{2}$ emissions in the $\mathrm{B} 2$ baseline scenario and in the $\mathrm{CO}_{2}$ mitigation scenario in the case of learning CCTs (B2-550t). The shaded areas depict sources of $\mathrm{CO}_{2}$ reductions in the global energy system of the mitigation scenario compared to the baseline scenario. 
coal technologies. GCC's comparatively low carbon intensity and electricity generation costs makes GCC to a "transitional" technology, accomplishing a smooth and costeffective transition to more pronounced changes in the energy structure in the latter half of the century. Generally, the pressure on the energy system to reduce emissions increases with time, since the reduction requirements in absolute quantities increases (Table 2). Eventually, this leads to the large-scale introduction of more costly abatement options, such as renewable energy and carbon capture from fossil fuels (Figs. 7 and 8).

As illustrated by the results, each of the three main mitigation measures is important, and none of the suggested mitigation options alone is sufficient to meet a 550-ppmv stabilization target. Hence, we conclude that effective mitigation strategies have to take into account the whole portfolio of technological possibilities, which includes also carbon capture with subsequent sequestration.

\subsection{Potentials for carbon scrubbing and removal}

The previous section analyzed the important role of carbon capture technologies as compared to other principal mitigation measures. In this section, we will focus on CCTs only. In particular, we will review estimates of global storage possibilities for the disposal of $\mathrm{CO}_{2}$ and compare them with the carbon sequestration figures in the scenarios. In addition, we present the underlying assumptions for costs and performance of CCTs in the scenarios and analyze their dynamics of market penetration. Finally, we conclude on potentials and macroeconomic costs of carbon capture assuming technological learning for CCT vs. no learning (static costs).

\subsubsection{Global carbon storage capacities}

Generally, $\mathrm{CO}_{2}$ removal by scrubbing and $\mathrm{CO}_{2}$ recovery from flue gases is referred to as "add-on" environmental strategies. After its recovery from the energy system, $\mathrm{CO}_{2}$ has to be disposed of, stored or otherwise used. One example of putting it to productive use is enhanced oil recovery, where $\mathrm{CO}_{2}$ is injected in oil fields (originally to improve the oil recovery rate). $\mathrm{CO}_{2}$ may also be stored in depleted natural gas and other underground reservoirs, eventually also in the deep ocean (Marchetti, 1989).

Original natural-gas production sites alone correspond to a potential storage capacity of about $150 \mathrm{Gt}$ C. After the extraction of higher cost gas categories, this storage capacity may be larger than 250 Gt C. The Second Assessment Report of the IPCC estimated the potential storage capacity of depleted oil and gas fields alone to be as high as 500 Gt C (IPCC, 1996). If structural traps are needed for secure storage, deep subterranean sandstone aquifers have a long-term $\mathrm{CO}_{2}$ storage capacity of at least $60 \mathrm{Gt}$ C (Hendriks, 1994). Without structural traps, the estimated worldwide sequestering capacity of aquifers is about $15,000 \mathrm{Gt} \mathrm{C} . \mathrm{CO}_{2}$ is also stored in chemical feedstocks and basic materials, e.g., $\mathrm{CO}_{2}$ is used in the synthesis of urea ( $>10 \mathrm{Mt} \mathrm{C}$ p.a.). By far, the largest reservoir for carbon disposal in the form of solid $\mathrm{CO}_{2}$ ice is the deep ocean, which currently stores about 36,000 Gt C. Orders of magnitude estimates for the main global sequestration options are presented in Table 3. Various methods of storing carbon in solid form have also been proposed (e.g., Yamada et al., 1992; Steinberg, 
Table 3

Global carbon sequestration capacities (Gt C)

\begin{tabular}{ll}
\hline Storage option & Capacity (Gt C) \\
\hline Depleted oil and gas reservoirs & hundreds \\
Deep saline quifiers & hundreds to thousands \\
Coal seams & tens to hundreds \\
Ocean & thousands
\end{tabular}

Source: Herzog (2001).

1996). ${ }^{9}$ Ongoing research and development is analyzing the technical and economic feasibility of these and other novel concepts for carbon capture and sequestration.

In none of the stabilization scenarios does the cumulative carbon sequestration from 1990 to 2100 exceed 300 Gt C (see Table 1). This means that the amount of carbon emissions that has been captured in the scenarios is well below the maximum potential of storage capacity of depleted oil and gas fields alone. Even though it seems that global storage possibilities are abundant compared to the sequestration requirements of the scenarios, it still has to be proved that the reservoirs proposed for carbon sequestration are effective, safe, and environmentally sound. Given the widespread deployment of CCT technologies in the scenarios, a better scientific understanding of the long-term fate of $\mathrm{CO}_{2}$ in storage reservoirs appears to be called for.

\subsubsection{Costs of carbon capture and sequestration}

There are many viable and promising methods for $\mathrm{CO}_{2}$ separation and capture from power plants. The most likely options currently identified are (U.S. DOE [Department of Energy], 1999)

- chemical and physical absorption,

- chemical and physical adsorption,

- low-temperature distillation,

- gas separation membranes, and

- minearalization and biomineralization

The capturing of $\mathrm{CO}_{2}$ accounts for about three-fourths of the total cost of a carbon capture, storage, transport, and sequestration system. The cost assumptions in the scenarios are based upon estimates from several recent studies (Rubin et al., 2001; EPRI and USDOE, 2000; Simbeck, 1999; Herzog, 1999) assuming that $\mathrm{CO}_{2}$ is captured from flue gases by currently available chemical absorption systems. For transportation and disposal, we assumed that captured $\mathrm{CO}_{2}$ is transported in liquid state, through $250 \mathrm{~km}$ of pipeline and disposed of in geological formations. The cost for $\mathrm{CO}_{2}$ transportation is based on estimates from the IEA (1999), assuming originally a distance of $500 \mathrm{~km}$ at US\$45/t C. Here, half the distance and an economy of scale factor of $2 / 3$, which results in US\$28/t C

9 Carnol System $\mathrm{CO}_{2}$ Reduction: When methanol is used in automotive internal combustion engines, a $\mathrm{CO}_{2}$ reduction by $56 \%$ compared to conventional system of coal plants and gasoline engines is achieved, and a $\mathrm{CO}_{2}$ reduction by as much as $77 \%$ when methanol is used in fuel cells in automotive engines (Steinberg, 1996). 
Table 4

Total carbon reduction costs, illustrated on the basis of two reference plants: (1) standard coal power plant, (2) natural gas combined cycle power plant

\begin{tabular}{|c|c|c|c|c|c|}
\hline & \multirow[t]{3}{*}{ Unit } & \multicolumn{2}{|l|}{ Coal } & \multicolumn{2}{|c|}{ Natural gas } \\
\hline & & \multicolumn{2}{|c|}{ Reference technology } & \multicolumn{2}{|c|}{ Reference technology } \\
\hline & & $\begin{array}{l}\text { Standard coal } \\
\text { power plant }\end{array}$ & Incl. CCT & NGCC & Incl. CCT \\
\hline Investment costs & $\$ / \mathrm{kW}$ & 1000 & 1749 & 730 & 1089 \\
\hline Fixed O\&M costs & $\$ / \mathrm{kW}$ & 27 & 20.7 & 52 & 78.1 \\
\hline Variable O\&M costs & $\$ / \mathrm{kW}$ year & n.a. & 188.7 & n.a. & n.a. \\
\hline Efficiency & $\%$ & 40 & 30.4 & 50 & 42.5 \\
\hline Plant life & years & 30 & 30 & 30 & 30 \\
\hline Plant factor & $\%$ & 65 & 65 & 65 & 65 \\
\hline Fuel cost & $\$ / G J$ & 1.75 & 1.75 & 3.53 & 3.53 \\
\hline Levelized investment costs & mills $/ \mathrm{kW} \mathrm{h}$ & 11.8 & 20.6 & 8.6 & 12.9 \\
\hline Levelized O\&M costs & mills $/ \mathrm{kW} \mathrm{h}$ & 4.8 & 30.4 & 9.2 & 13.8 \\
\hline Levelized fuel costs & mills $/ \mathrm{kW} \mathrm{h}$ & 15.7 & 20.7 & 25.4 & 29.9 \\
\hline Electricity generation costs & mills $/ \mathrm{kW} \mathrm{h}$ & 32.3 & 71.8 & 43.2 & 56.5 \\
\hline Carbon emissions & $\mathrm{g} \mathrm{C} / \mathrm{kW} \mathrm{h}$ & 232 & 30 & 110 & 13 \\
\hline Total carbon reduction costs & $\$ / t \mathrm{C}$ & - & 196 & - & 137 \\
\hline
\end{tabular}

of transport plus disposal cost is assumed. Technology costs and performance assumptions for coal- and natural-gas-based reference plants and the respective carbon capture plants are summarized in Table 4. Generally, the capturing of $\mathrm{CO}_{2}$ is associated with efficiency losses of the power generation process and additional costs for the carbon capture facilities. As shown in Table 4, the carbon abatement costs for coal technologies resulting from our assumptions are US\$196/t C, compared to US\$137/t C for natural gas (both figures including transportation and disposal). ${ }^{10}$

In the stabilization scenarios with static costs (A2-550s, B2-550s), we assumed that the capital costs for CCTs remain constant over time, at the values shown in Table 4. In contrast, in the case of learning CCTs (A2-550t, B2-550t), we assumed that their costs decrease with accumulated experience in CCT construction. As described in Section 2, the investment cost declines by $13 \%$ for each doubling of CCT capacity. The development of carbon reduction costs as a function of cumulative installed CCT capacities in the scenarios is illustrated in Fig. 9.

Due to technological learning, CCT costs drop rapidly in the stabilization scenarios, leading to cost reductions by a factor of 4 by the end of the century. In line with the development of costs, CCT technologies diffuse pervasively into the energy markets, accomplishing the continuous use of fossil fuels at relatively modest costs and low carbon emissions. Total reduction costs for natural-gas technologies drop to US\$34-38/t C, and those of coal technologies to US\$41-61/t C (Fig. 9). ${ }^{11}$

\footnotetext{
${ }^{10}$ Costs of carbon removal in synthetic fuels production (and from IGCC) were assumed to be US\$46/t C (inclusive transportation and disposal).

11 As to initial carbon reduction costs for CCTs, both scenarios (A2 and B2) share the same assumptions for coal-based CCTs (US\$196/t C) and natural gas-based CCTs (US\$137/t C).
} 


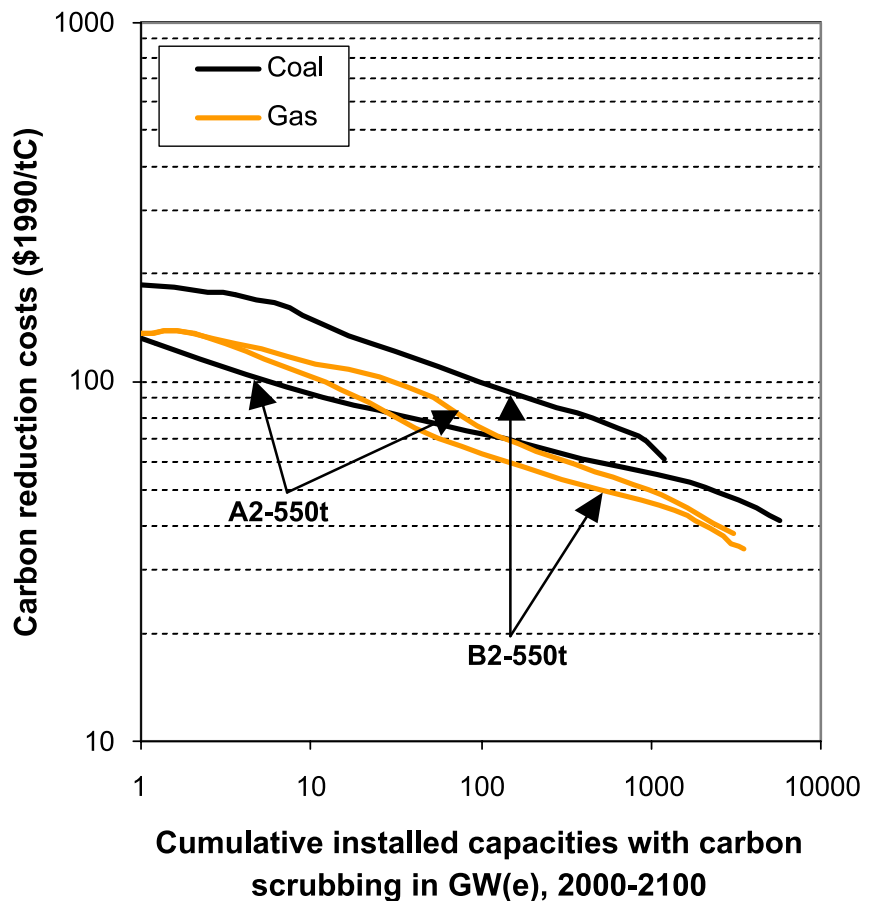

Fig. 9. Technological learning of carbon capture technologies in the A2-550t and B2-550t scenarios, illustrated as decreasing specific carbon reduction costs over accumulated experience (cumulative installed power generation capacities).

The development of the carbon reduction costs for CCTs depend also on regional resource availability and the development of fuel costs. In addition, assumptions on technological change for the power plants themselves influence the carbon reduction costs of CCTs. A sensitivity analysis using different initial costs for CCTs suggests that the learning rate might be the most decisive factor, not only for the costs, but also for the successful diffusion and dissemination of CCTs (given a specific carbon constraint). ${ }^{12}$

\subsubsection{CCT market shares in the electricity sector}

The scenario's market shares of CCT technologies are the result of complex interactions between demand-pull to supply-push activities. On the demand side, the carbon concentration limit enforces the introduction of new and advanced technologies with low carbon intensities. On the supply side, increasing returns from induced technological learning of

\footnotetext{
12 Our iterative approach to approximating learning curves by time series is not perfect. This is why the two black curves for coal technology in Fig. 9 do not emanate from one and the same point (such as the two curves for gas). Forcing them to have the same initial costs (at one GW cumulative capacity) would have led to either inconsistent time profiles of cost developments or to cost lines that would not have resembled straight lines. We therefore opted for the approximation (and the error) shown in the figure.
} 
CCTs pushes their market penetration from the supply side. Together, this results in very successful penetration of CCT technologies in the scenarios with technological learning, compared to scenarios with static cost assumptions.

Fig. 10 depicts the diffusion of carbon capture technologies (added to natural-gas and coal technologies) into the electricity generation market in the case of technological learning for CCTs. The graph shows the increasing shares of $\mathrm{CO}_{2}$ capture plants, depicting examples of very successful market introduction. Initially, CCTs are expensive and limited in their application. They have to first prove themselves during the demonstration phase where performance rather than costs is the overriding criterion. Then subsequent improvements and cost reductions lead to wider application. Finally, growth rates slow down as markets become saturated. The diffusion of CCTs proceeds along a typical S-shaped pattern: slow at the beginning, followed by accelerating growth that ultimately slows down as markets become saturated. The literature on S-shaped diffusion is large, and there have been many studies, which have applied these curves to the spread of, e.g., transportation infrastructures and other types of technologies (Marchetti, 1983; Haegerstrand, 1967; Fisher and Pry, 1971; Nakicenovic, 1986; Grübler, 1998b).

Comparing the diffusion of CCTs in scenarios with learning (A2-550t, B2-550t) with those assuming constant costs of these technologies (A2-550s, B2-550s) shows that the market penetration of CCTs is accelerated due to technological learning. Particularly, the carbon capture from coal technologies benefits considerably from the learning effect, leading to global market shares of more than $90 \%$ in 2100 (compared to $60-70 \%$ in the
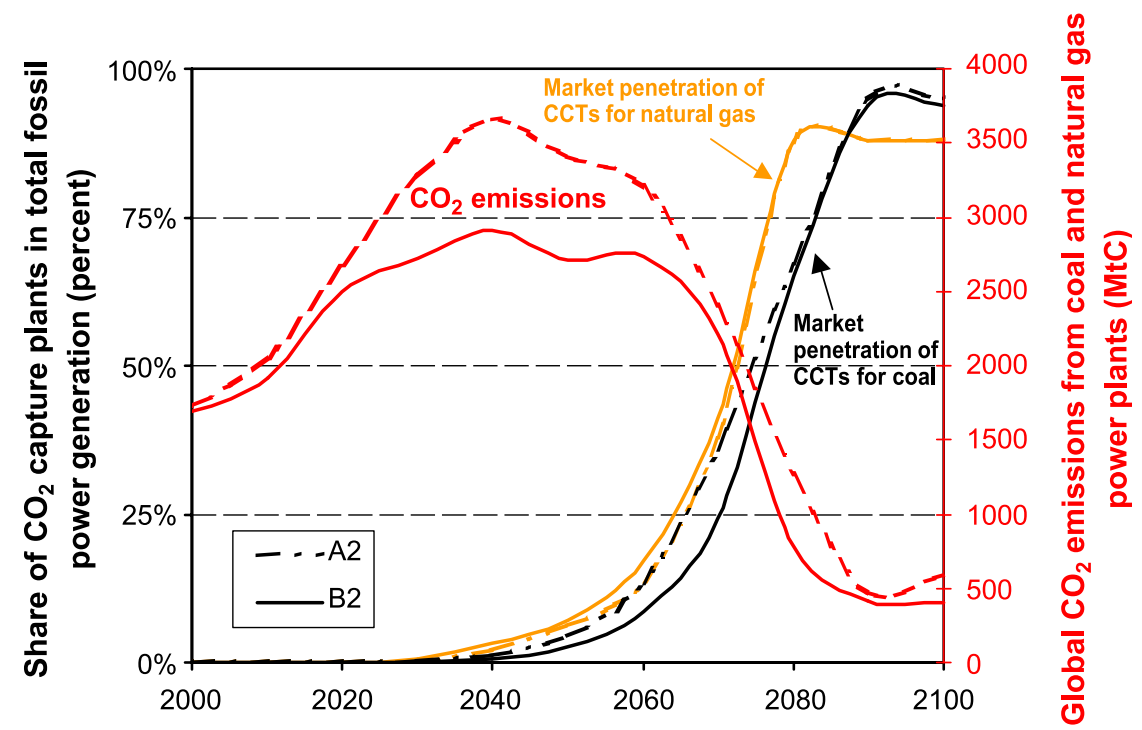

Fig. 10. Market penetration of "learning" CCT technologies for natural-gas and coal power plants in the A2-550t and B2-550t scenarios (left-hand axis). Dashed lines depict the development in the A2-550t scenario and uninterrupted lines in B2-550t. Also shown are the aggregated $\mathrm{CO}_{2}$ emissions from coal and natural-gas power generation in the respective scenarios (right-hand axis). 
case of static costs). At the end of the century, almost all fossil power plants are equipped with carbon capture technologies in the case of learning (Fig. 10).

The resulting $\mathrm{CO}_{2}$ emissions from coal and natural-gas-based power generation are also shown in Fig. 10. The $\mathrm{CO}_{2}$ emissions path in the scenarios follows an inverse U-shaped pattern similar to the environmental Kuznets curves observed for other pollutant emissions in the past, such as sulfur (Grübler, 1998a). After an initial growth phase, $\mathrm{CO}_{2}$ emissions peak around the middle of the century and later decline, when the carbon capture and sequestration technologies gain considerable market share. Most notably, until the end of the century, global $\mathrm{CO}_{2}$ emissions from coal and gas power generation decreases by more than a factor of 3 , while power generation from these technologies grows to three to five times their present production (about $27 \mathrm{EJ}$ ).

Another characteristic of the scenarios is the comparatively late diffusion of CCTs. It requires decades for them to diffuse widely. In all four stabilization scenarios, large-scale applications first emerge as late as in the 2030s. However, once introduced, they continuously gain market shares. The entire diffusion of CCTs, from the initial introduction to saturation, spans, in all scenarios, about 50 years, which is similar to diffusion speeds of other types of technologies found in the literature (see, e.g., Grübler and Nakicenovic, 1991). Most importantly, our results should not be interpreted as a pretext to wait decades and then start the installation of CCTs. In fact, to realize the technology diffusion shown by the stabilization scenarios requires early action, including the creation of niche markets, the development of small-scale demonstration plants, and targeted R\&D.

\subsubsection{Cumulative carbon sequestration}

The scenario's total cumulative carbon sequestration by time period-from 1990 to the years 2020, 2050, and 2100 respectively - are shown in Fig. 11. Generally, the amounts scrubbed depend strongly on (1) the socioeconomic and technological assumptions in the baseline scenarios and (2) the assumptions with respect to technological learning for CCT technologies. As illustrated in Fig. 11, cumulative carbon sequestration is higher in the

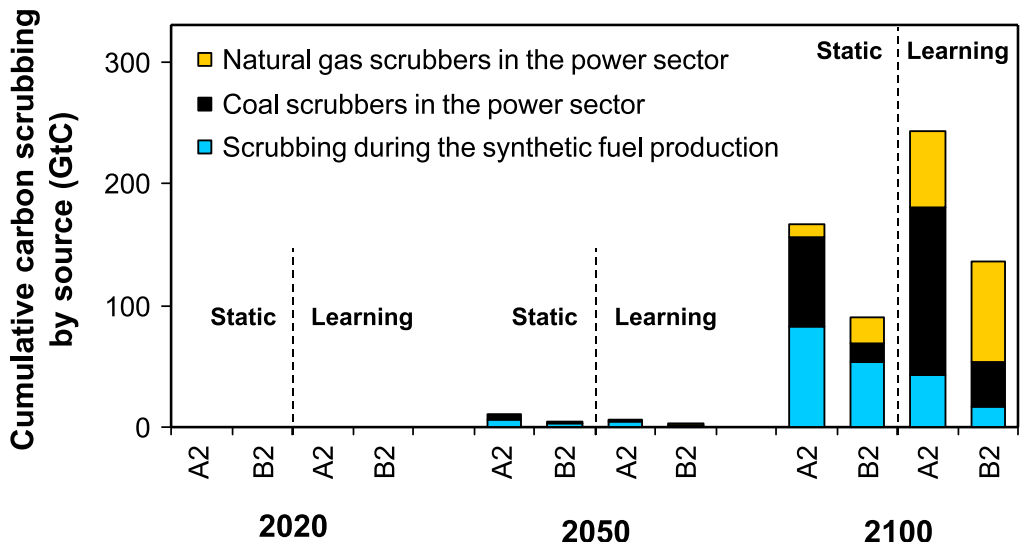

Fig. 11. Cumulative carbon capture and sequestration by source. Learning for CCT leads to comparatively high deployment of carbon capture technologies, in particular, in the electricity sector. 
case of the A2 scenario compared to the B2 scenario and higher in scenarios with CCTs with learning than in those with static cost assumptions.

Since the A2 baseline depicts a future of heavy reliance on coal technologies, cumulative carbon sequestration is particularly high in A2, calling for environmentally compatible solutions that permit the continuous use of coal at low carbon emissions. In contrast, fossil-based power generation plays a less prominent role in the B2 baseline scenario and is mainly dominated by advanced natural-gas technologies, in particular gascombined-cycle. Hence, in A2, coal scrubbers dominate, while in B2, natural-gas scrubbers account for the bulk of the emissions reductions (Fig. 11).

The relatively fast and more complete market diffusion of CCTs in the case of learning results also in considerably higher cumulative carbon sequestration (when compared to the scenarios with static CCT costs). In the case of learning, CCT's cumulative carbon emissions from 1990 to 2100 range between 137 and $243 \mathrm{Gt} \mathrm{C}$. This corresponds to a 50\% increase of sequestration due to learning effect for CCTs, compared to the scenarios with static CCT costs (90-167 Gt C).

\subsubsection{Impact on the electricity price}

The development of electricity prices in the baseline and the stabilization scenarios is shown in Fig. 12. As for total energy demand (see Section 4.2), electricity consumption is reduced in the stabilization cases compared to their respective baselines. This is due to the assumed price elasticity of electricity demand, which leads to demand reductions in response to higher prices in all mitigation cases, compared to the baseline scenarios. Due to the lower costs for CCT, the price increase is less pronounced in stabilization scenarios with learning CCTs than in the cases with static CCT costs.

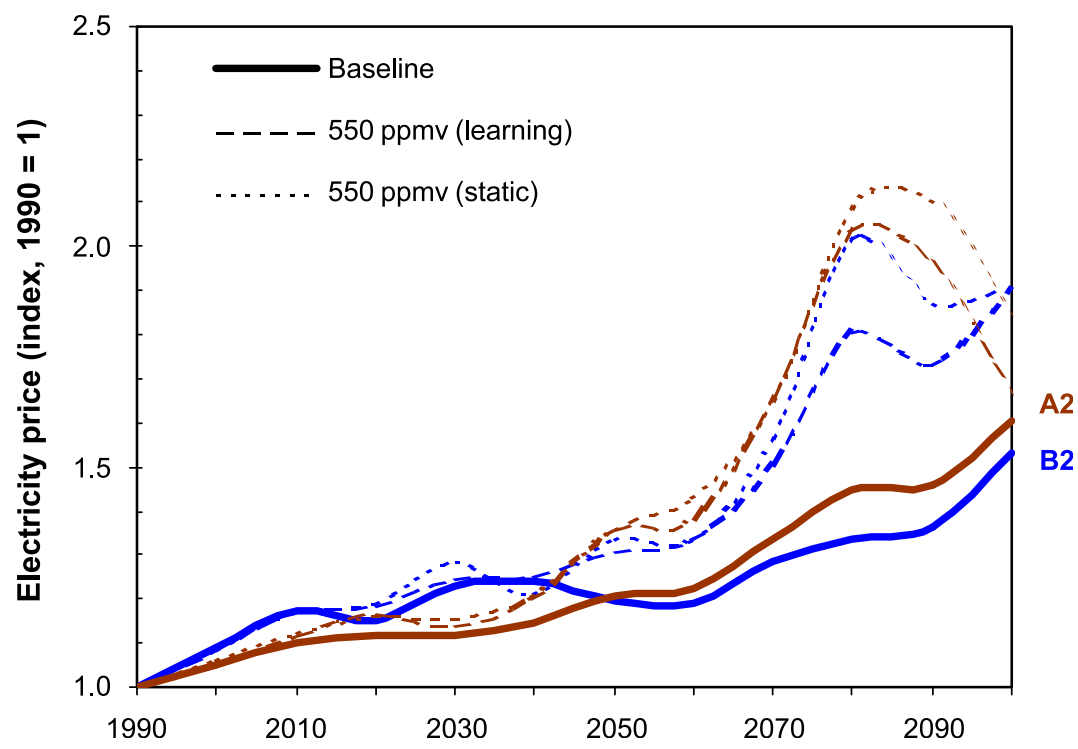

Fig. 12. Development of electricity prices in the scenarios. 
Table 5

Carbon values in four stabilization scenarios

\begin{tabular}{llll}
\hline & \multicolumn{2}{l}{ Carbon tax $(1990$ US\$/t C) } & 2100 \\
\cline { 2 - 4 } & 2020 & 2050 & 496 \\
\hline Static CCT costs & 25 & 82 & 447 \\
A2-550s & 23 & 59 & \\
B2-550s & & & 490 \\
Learning CCTs & 19 & 27 & 406 \\
A2-550t & 18 & 64 & \\
B2-550t & & & \\
\hline
\end{tabular}

The carbon values are an endogenous result of the model calculations and can be interpreted as the carbon tax that is required to meet the 550 ppmv stabilization target.

\subsubsection{Carbon values and macroeconomic costs of the emissions reduction}

Table 5 shows the resulting carbon values in the mitigation scenarios. The carbon value is an endogenous output calculated by the MESSAGE model. It can be interpreted as the average carbon tax that has to be introduced in a carbon-constrained world in order to meet the stabilization target. Due to steadily increasing emissions in the baselines, the pressure on the global energy system to reduce emissions increases over time, particularly in the latter half of the century. In the stabilization scenarios, carbon values grow steadily from about US\$20/t C in 2020 to about US\$400-500/t C in 2100. Due to the increasing cost effectiveness of CCTs in the case of learning, the required carbon value (tax) is lower in stabilization scenarios with dynamic CCT costs, compared to those based on static costs. This result illustrates that assumptions on technological change is one of the most decisive factors in determining the cost effectiveness of long-term carbon abatement policies (see also Roehrl and Riahi, 2000).

Table 6 summarizes the macroeconomic costs of the emissions reductions, measured as the loss of global gross domestic product (GDP) in the stabilization scenarios, compared to the respective baselines.

Table 6

Global gross domestic product (GDP) and GDP losses from the reference case to the stabilization scenarios for the year 2100

GDP (trillion 1990US\$)

GDP losses (percent of baseline)

\section{Baseline scenarios}

A2

B2

\section{Static CCT costs}

A2-550s

B2-550s

236.4

230.8
242.8

234.9

\section{Learning CCTS}

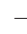

B2-550t 
GDP losses are generally higher in the A2 stabilization scenarios (2.6\% in 2100) than in B2 (1.7\% in 2100), once more illustrating the importance of the socioeconomic and technological assumptions in the baseline scenarios in determining the choice and costs of mitigation strategies.

One striking result of our analysis is that the GDP losses do not differ significantly in the case of learning CCTs, compared to scenarios with static CCT costs. There seems to be no direct relationship between total amounts of cumulative carbon sequestration and GDP losses, indicating that the macroeconomic stabilization cost is the result of a more complex price formation system, in which CCTs are just one influencing factor among many. CCT costs contribute to the progression of prices, but do not completely determine them.

The range of GDP losses given in Table 6 are comparable to results from similar studies. For example, Edmonds and Richels (1995) report losses of $0.5-1 \%$ for a 500 -ppmv stabilization constraint. Results for a 550-ppmv stabilization case from the 14th Energy Modeling Forum Study for four different models (CSERGE, CETA, PEF, and CONN) suggest losses between $0.4 \%$ and $3.4 \%$ of GDP (EMF14, 1994). Most notably, however, the GDP losses in all of our stabilization scenarios are rather small, compared to the scenario's increase of total GDP by a factor of 11 (from 1990 to 2100), which illustrates that atmospheric carbon concentration stabilization at $550 \mathrm{ppmv}$ is possible at moderate costs.

\section{Summary and conclusions}

In this report, we have estimated future potentials of carbon capture and sequestration technologies (CCT) in the framework of global greenhouse gas emissions scenarios of economic, demographic, and energy demand development, where alternative policy cases lead to the stabilization of atmospheric $\mathrm{CO}_{2}$ concentrations at $550 \mathrm{ppmv}$. In contrast to several other scenario analyses where technology costs and performance are assumed to stay constant over time, we have analyzed the future prospects of CCT technologies using a more dynamic representation of technology. In particular, we quantified a "learning curve" for CCT, which describes the relationship between specific cost reductions and the accumulation of experience in CCT deployment. To do this, we examined past experience with managing other major power plant emissions that may serve as a reasonable guide to technological progress in managing $\mathrm{CO}_{2}$ emissions. In particular, we focused on the experience made over the past 30 years in the US and other countries with reducing emissions of sulfur dioxide $\left(\mathrm{SO}_{2}\right)$ using flue gas desulfurization (FGD) systems. This technology (commonly known as $\mathrm{SO}_{2}$ "scrubbers") employs principles of operation that are similar to those employed in currently commercial $\mathrm{CO}_{2}$ capture systems. These systems use chemical sorbents to remove $\mathrm{CO}_{2}$ from gas mixtures, such as combustion products. For FGD systems, investment costs declined by $13 \%$ for each doubling of capacity worldwide, and this is therefore the value we used to quantify the learning curve for CCTs.

Part of the integrated assessment was to analyze the potential of CCTs in the context of other possible carbon mitigation technologies and measures. We did this by including (learning) CCTs into the energy supply optimization model MESSAGE-MACRO, in which carbon capture and sequestration have to compete with other mitigation measures such as fuel switching and price-induced conservation. Our analysis shows that the timing, 
costs, and contribution of carbon mitigation measures strongly depend on (1) the socioeconomic and technological assumptions included in the baseline scenario and (2) the assumed learning potential of carbon capture and sequestration technologies. Assuming that learning in CCT technology deployment proceeds at a similar pace as in $\mathrm{SO}_{2}$ abatement technologies in the past, the long-term carbon emission reduction potential for CCTs is vast; in our scenarios ranging between 140 and $250 \mathrm{Gt} \mathrm{C}$ of cumulative $\mathrm{CO}_{2}$ sequestration (from 1990 to 2100 , assuming a stabilization target of $550 \mathrm{ppmv}$ ). This is particularly due to large-scale investments into CCT and the accumulation of experience, which leads to rapid cost decreases of these technologies. Even though their widespread deployment requires decades, CCTs gain much higher market shares in the case of learning, compared to scenario results with static CCT cost assumptions. At the end of the 21 st century, almost all fossil power plants are equipped with CCT in the case of learning. Thus, we conclude that carbon capture and sequestration is one of the obvious priority candidates for long-term technology policies and enhanced R\&D efforts to hedge against the risk associated with the high environmental impacts of climate change.

Our scenario analysis also showed that the capturing of carbon with subsequent sequestration might not be sufficient to meet a 550-ppmv stabilization constraint (in the year 2100), even in the case of learning and a very rapid market penetration for CCTs. In addition to carbon sequestration, reaching this goal must also include better energy efficiency and the increased use of low-carbon emitting energy sources, in particular fuel switching, primarily away from carbon-intensive coal to low or zero-carbon fuels.

Acknowledging the major differences between scenarios with learning CCTs and those with static cost assumptions leads us to two important conclusions. First, climate policy models should be capable of characterizing future changes in cost and performance resulting from technology innovation (learning). Second, climate policies need to be extended to include technology policies, in order to make the diffusion of environmentally sound technologies operational in the long run (as shown by our stabilization scenarios). This calls for early action to accomplish the required cost and performance improvements in the long term, including the creation of niche markets, the development of small-scale demonstration plants, and targeted R\&D.

\section{Acknowledgements}

This article results from our participation in Energy Modeling Forum Study 19. The authors are indebted to Bing Zhu and Takeyoshi Kato for valuable comments and research assistance. This research was funded by the Integrated Assessment Program, Biological and Environmental Research (BER), U.S. Department of Energy under Award Number DE-FG02-00ER63037. Any opinions, findings, conclusions or recommendation expressed herein are those of the authors and do not reflect the views of DOE, IIASA, or Carnegie Mellon University.

\section{References}

Dutton, J.M., Thomas, A., 1984. Treating progress ratios as a marginal opportunity. Academy of Management Review 9 (2), 235-247. 
Edmonds, J., Richels, R., 1995. The economics of stabilizing atmospheric $\mathrm{CO}_{2}$ concentrations. Energy Policy 23 (4-5), 370-373.

EMF14 (Energy Modeling Forum), 1994. Integrated Assessment of Climate Change Models. First round of scenario results. International Institute for Applied Systems Analysis, 2361 Laxenburg, Austria.

EPRI and USDOE, 2000. Evaluation of Innovative Fossil Fuel Power Plants with $\mathrm{CO}_{2}$ Removal. EPRI, Palo Alto, CA.

Fisher, J.C., Pry, R.H., 1971. A simple substitution model of technological change. Technological Forecasting and Social Change 3, 75-88.

Grübler, A., 1998a. A review of global and regional sulfur emissions scenarios. Mitigation and Adaptation Strategies for Global Change 3 (2-4), 383-418.

Grübler, A., 1998b. Technology and Global Change. Cambridge Univ. Press, Cambridge, UK.

Grübler, A., Nakicenovic, N., 1991. Evolution of Transport Systems: Past and Future. RR-91-8. International Institute for Applied Systems Analysis (IIASA), Laxenburg, Austria.

Haegerstrand, T., 1967. Innovation diffusion as a spatial process. University of Chicago Press, Chicago.

Hendriks, C., 1994. Carbon dioxide removal from coal-fired power plants. PhD thesis, Department of Science, Technology, and Society, Utrecht University, Utrecht, the Netherlands.

Herzog, H.J., 1999. The economics of $\mathrm{CO}_{2}$ capture. In: Eliasson, B., Reimer, P., Wokaum, A. (Eds.), Greenhouse Gas Control Technologies. Proceedings of the 4th International Conference on Greenhouse Gas Control Technologies, 30th August-2nd September 1998, Interlaken, Switzerland. Elsevier Science Ltd., Oxford, pp. 101-106 [ISBN: 008043018X Book].

Herzog, H.J., 2001. What future for carbon capture and sequestration. Environmental Science and Technology 35 (7), 148A-153A.

IEA (International Energy Agency), 1999. Ocean Storage of $\mathrm{CO}_{2}$, IEA Greenhouse Gas R\&D Programme, Gloucestershire, UK.

IEA (International Energy Agency), 2000. Experience Curves for Energy Technology Policy. IEA Publications, France, Paris (ISBN 92-64-17650-0).

IPCC (Intergovernmental Panel on Climate Change), 1996. Climate change 1995: impacts, adaptations, and mitigation of climate change: scientific-technical analyses. In: Watson, R.T., Zinyowera, M.C., Moss, R.H. (Eds.), 1996. Contribution of Working Group II to the Second Assessment Report of the Intergovernmental Panel on Climate Change. Cambridge Univ. Press, Cambridge, UK (880 pp.).

IPCC (Intergovernmental Panel on Climate Change), 2000. In: Nakicenovic, N., Alcamo, J., Davis, G., de Vries, B., Fenhann, J., et al. (Eds.), 2000. Special Report on Emissions Scenarios (SRES), A Special Report of Working Group III of the Intergovernmental Panel on Climate Change. Cambridge Univ. Press, Cambridge, UK.

Keeth, R.J., Ireland, P.A., Moser, R.E., 1986. Economic evaluation of twenty-four FGD systems. Paper presented at the $\mathrm{SO}_{2}$ Control Symposium, Atlanta, GA.

Keeth, R.J., Ireland, P.A., Radcliffe, P.T., 1990. 1990 update of FGD economic evaluations. Paper presented at the $\mathrm{SO}_{2}$ Control Symposium, New Orleans, LA.

Keeth, R.J., Ireland, P.A., Radcliffe, P.T., 1991. Economic evaluation of twentyeight FGD processes. Paper presented at the $\mathrm{SO}_{2}$ Control Symposium, Washington, DC.

Keeth, R.J., Ireland, P.A., Radcliffe, P.T., 1995. Utility response to Phase I and Phase II acid rain legislationan economic analysis. Paper presented at the EPRI/DOE/EPA $1995 \mathrm{SO}_{2}$ Control Symposium, Miami Beach, FL.

Marchetti, C., 1983. Innovation, Industry and Economy-A Top-Down Anaysis. PP-83-6. International Institute for Applied Systems Analysis (IIASA), Laxenburg, Austria.

Marchetti, C., 1989. How to solve the $\mathrm{CO}_{2}$ problem without tears. International Journal Hydrogen Energy 14 (8), $493-506$.

McDonald, A., Schrattenholzer, L., 2001. Learning curves and technology assessment. Special Issue of the International Journal of Technology Management 8 (23).

McGlamery, G.G., Faucett, H.L., Torstrick, R.L., Henson, L.J., 1976. Flue gas desulfurization economics. Paper presented at the Symposium on Flue Gas Desulfurization, New Orleans, LA.

McGlamery, G.G., O’Brien, W.E., Stephenson, C.D., Veitch, J.D., 1980. FGD economics in 1980. Paper presented at the $\mathrm{SO}_{2}$ Control Symposium, Houston, TX. 
Messner, S., 1997. Endogenized technological learning in an energy systems model. Journal of Evolutionary Economics 7 (3), 291-313.

Messner, S., Schrattenholzer, L., 2000. MESSAGE-MACRO: linking an energy supply model with a macroeconomic module and solving it iteratively. Energy 25, 267-282.

Nakicenovic, N., 1986. The automotive road to technological change: diffusion of the automobiles as a process of technological substitution. Technological Forecasting and Social Change 29, 309-340.

Nakicenovic, N., Grübler, A., Inaba, A., Messner, S., Nilsson, S., et al., 1993. Long-term strategies for mitigating global warming. Special Issue of Energy 18 (5), 401-609.

Nakicenovic, N., Grübler, A., McDonald, A. (Eds.), 1998. Global Energy Perspectives. Cambridge Univ. Press, Cambridge, UK (ISBN 0521642000).

Riahi, K., Roehrl, R.A., 2000a. Greenhouse gas emissions in a dynamics-as-usual scenario of economic and energy development. Technological Forecasting and Social Change 63 (3), 175-205.

Riahi, K., Roehrl, R.A., 2000b. Energy technology strategies for carbon dioxide mitigation and sustainable. Environmental Economics and Policy Studies, vol. 3 (2). Springer, Tokyo, pp. 89-123.

Roehrl, R.A., Riahi, K., 2000. Technology dynamics amd greenhouse gas emissions mitigation-a cost assessment. Technological Forecasting and Social Change 63 (3), 231-261.

Rubin, E.S., 1983. International costs of environmental control for coal-fired boilers. Environmental Science and Technology 17 (8), 366A-377A.

Rubin, E.S., Kalagnanam, J.R., Frey, H.C., Berkenpas, M.B., 1997. Integrated environmental control modeling of coal-fired power systems. Journal of the Air and Waste Management Association 47, 1180-1188.

Rubin, E.S., Rao, A.B., Berkenpas, M.B., 2001. A multi-pollutant framework for evaluating $\mathrm{CO}_{2}$ control options 755 for fossil fuel power plants. Proceedings of First National Conference on Carbon Sequestration. US Department of Energy, Washington, DC, $18 \mathrm{pp}$. http://www.netl.doe.gov/publications/proceedings/01/ carbon_seq/carbon_seq01.html

Simbeck, D., 1999. A portfolio selection approach for power plant $\mathrm{CO}_{2}$ capture, separation and R\&D options. In: Eliasson, B., Reimer, P., Wokaum, A. (Eds.), Greenhouse Gas Control Technologies. Proceedings of the 4th International Conference on Greenhouse Gas Control Technologies, 30th August-2nd September 1998, Interlaken, Switzerland. Elsevier Science Ltd., Oxford, pp. 119-124 [ISBN: 008043018X Book].

Soud, H.N., 1994. FGD Installations on Coal-Fired Plants. IEA Coal Research, London.

Steinberg, M., 1996. The Carnol System for Methanol Production and $\mathrm{CO}_{2}$ Mitigation from Coal Fired Power Plants and the Transportation Sector. U.S. Department of Energy, US EPA Research Triangle Park NC.

Strubegger, M., McDonald, A., Gritsevskii, A., Schrattenholzer, L., 1999. CO2DB Manual, Version 2.0, April, 1999 IIASA, Laxenburg, Austria (17 pp.).

Taylor, M., 2001. The influence of government actions on innovative activities in the development of environmental technologies to control sulfur dioxide emissions from stationary sources. $\mathrm{PhD}$ thesis, Carnegie Mellon University, Pittsburgh, PA, January 2001.

UN (United Nations), 1998. World Population Projections to 2150. United Nations Department of Economic and Social Affairs Population Division, New York, NY, USA.

U.S. DOE (Department of Energy), 1999. Carbon Sequestration-Research and Development, U.S. Department of Energy, Washington, DC 20585 (www.doe.gov/bridge).

Wigley, T.R., Richels, R., Edmonds, J., 1996. Economic and environmental choices in the stabilization of atmospheric $\mathrm{CO}_{2}$ concentrations. Nature 359 (6562), 240-243.

Wright, T.P., 1936 (February). Factors affecting the costs of airplanes. Journal of the Aeronautical Sciences 3, $122-128$.

Yamada, K., Yonishi, K., Okada, O., Steinberg, M., 1992. Evaluation of hydrocarb process for $\mathrm{CO}_{2}$. Removal, Energy Conversion Management 33 (5-8), 437-441 (Pergamon). 


\section{Ordering Information}

Orders must include the publication number and should be sent to the Publications Department, International Institute for Applied Systems Analysis, A-2361 Laxenburg, Austria.

Telephone: +432236807

Telefax: +432236 71313

E-mail: publications@iiasa.ac.at

A full list of IIASA publications is available at www.iiasa.ac.at/Publications 
International Institute for Applied Systems Analysis

Schlossplatz 1, A-2361 Laxenburg, Austria

Tel: +432236 807 Fax: +43 223671313

I I AS A www.iiasa.ac.at 